\title{
Chest RADIOLOGY
}

\section{Dendriform pulmonary ossification: Report of two cases}

\author{
Lamia Jamjoom, Moulay Meziane, Rahul D Renapurkar \\ Department of Radiology, Imaging Institute, Thoracic Imaging, Imaging Institute, Cleveland Clinic, Cleveland, Ohio, United States
}

Correspondence: Dr. Rahul D. Renapurkar, Section of Thoracic Imaging, Imaging Institute, 9500 Euclid Avenue, Cleveland, Ohio 44195, United States. E-mail: renapur@ccf.org

\begin{abstract}
Dendriform pulmonary ossification is a rare form of diffuse pulmonary ossification that is usually detected incidentally on chest radiographs or chest computed tomography (CT) imaging. In this article, we present two patients who were incidentally found to have dendriform pulmonary ossification on chest imaging. The article will present the history and imaging findings of these two cases and then review the clinical, histological, and radiographic manifestations of dendriform pulmonary ossification.
\end{abstract}

Key words: Dendriform pulmonary ossification; chest radiography; computed tomography.

\section{Introduction}

Diffuse pulmonary ossification is a chronic process characterized by progressive metaplastic ossification. Since patients with this condition are usually asymptomatic, the diagnosis may only be made on autopsy or surgical pathology specimens. ${ }^{[1]}$ Two forms of diffuse pulmonary ossification are described in literature: The relatively more common nodular type and the rarer dendriform type. We report two patients who underwent chest computed tomography (CT) imaging in whom we incidentally found dendriform pulmonary ossification (DPO).

The first patient, a 79-year-old non-smoker, had been in his usual state of health until March 2009, when he was admitted to the hospital with pneumonia and bacteremia. He had since then had progressively increasing shortness of breath. His pulmonary function tests showed severe restriction, with forced vital capacity (FVC) of $42 \%$ and moderately reduced diffusion capacity. A chest radiograph revealed cardiomegaly and multifocal

\begin{tabular}{|l|l|}
\hline \multicolumn{2}{|c|}{ Access this article online } \\
\hline Quick Response Code: & Website: \\
\hline & www.ijri.org \\
\cline { 2 - 3 } & \\
\cline { 2 - 3 } & DOI: \\
\hline
\end{tabular}

interstitial opacities throughout both lung fields [Figure 1]. To further characterize the disease process, a chest CT was ordered. CT revealed mild centrilobular emphysema, air trapping, and diffuse bilateral calcified nodular densities [Figures 2 and 3] that were seen extending in a linear and branching pattern. An open lung biopsy was performed and showed dystrophic calcium with osseous metaplasia (early bone formation) [Figure 4]. No other pathology was detected.

The second patient was a 77-year-old male who presented with a recent diagnosis of bladder carcinoma. The patient had a past medical history of coronary artery disease, stroke, hypertension, and hypercholesterolemia. He was a former smoker who had quit tobacco 30 years prior to his presentation. His occupational history was remarkable for asbestos exposure. His pulmonary function tests were normal. CT of the chest was done as part of the staging procedure. CT showed multiple scattered peripheral linear and branching nodular densities, most of which were calcified. The lesions were more marked in the lower lobes [Figures 5 and 6].

\section{Discussion}

Pulmonary calcifications are extremely common findings in chest imaging and can occur in a multitude of conditions. The common causes of pulmonary calcifications and ossifications are listed in Table 1. Diffuse pulmonary ossification is a chronic metaplastic process characterized 


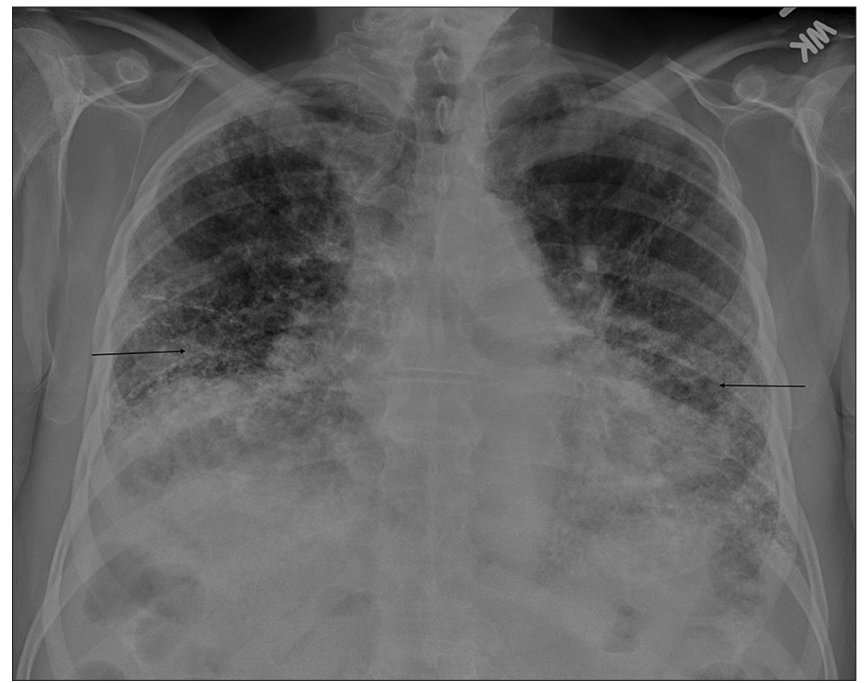

Figure 1: Chest X-ray shows patchy bilateral interstitial opacities in both lungs (arrows)

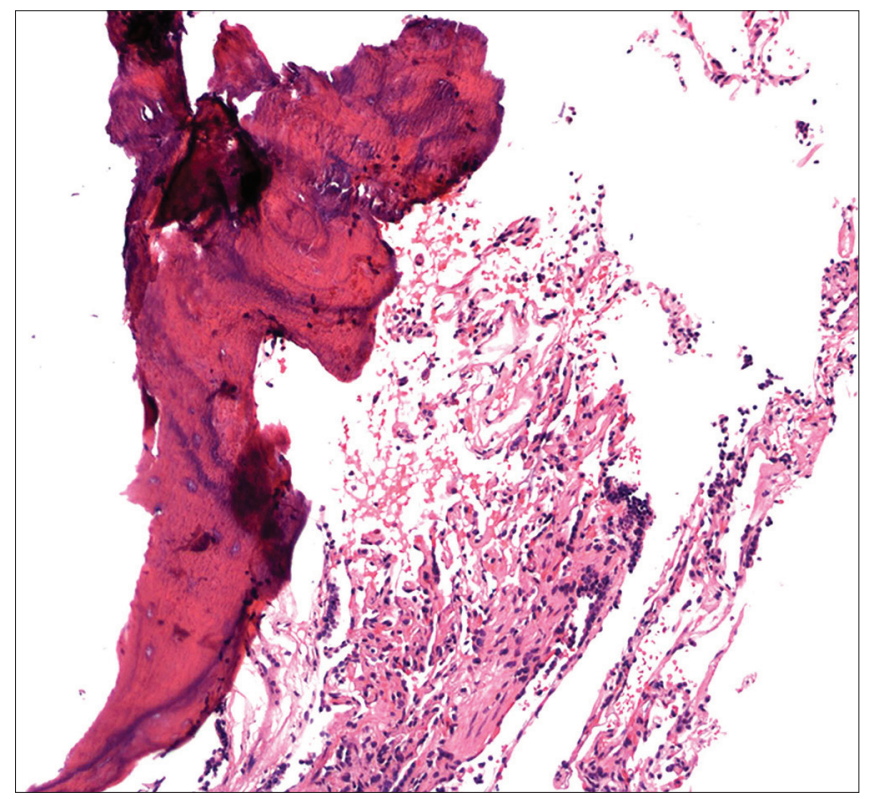

Figure 4: Ossification (left) adjacent to benign, unremarkable, lung alveoli (right) $(\mathrm{H}$ and $\mathrm{E}, \times 100)$

by the histologic presence of mature bone in the interstitial or alveolar spaces. ${ }^{[2]}$ It is a rare asymptomatic entity that is associated with diffuse and chronic cardiac or pulmonary disease or other systemic disorders such as amyloidosis. Diffuse pulmonary ossification is a marker of the chronicity and/or severity of the process. When the disease is extensive, lung function shows a restrictive pattern and low diffusing capacity.

Diffuse pulmonary ossification has been recognized in two forms: Granular (nodular) and dendriform. ${ }^{[3]}$ Of the two entities, dendriform pulmonary ossification is less common.

The nodular form of pulmonary ossification usually occurs in the context of chronic congestion such as in
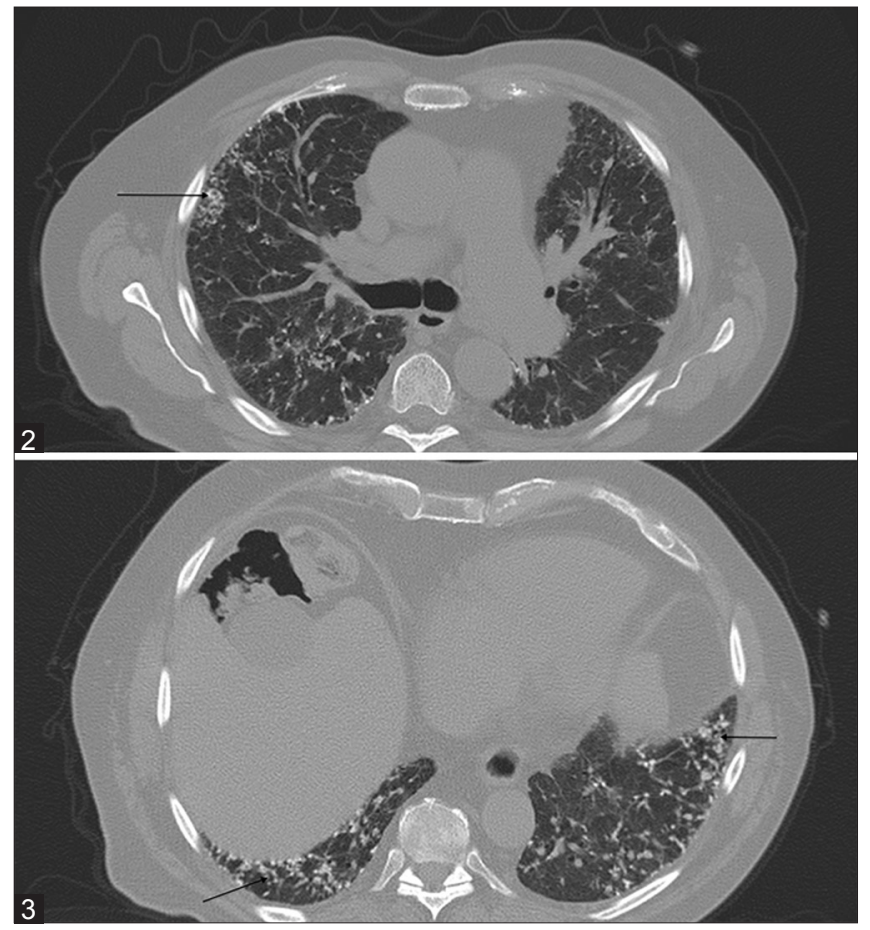

Figures 2 and 3: CT images show the branching calcific densities in both lungs (arrows)

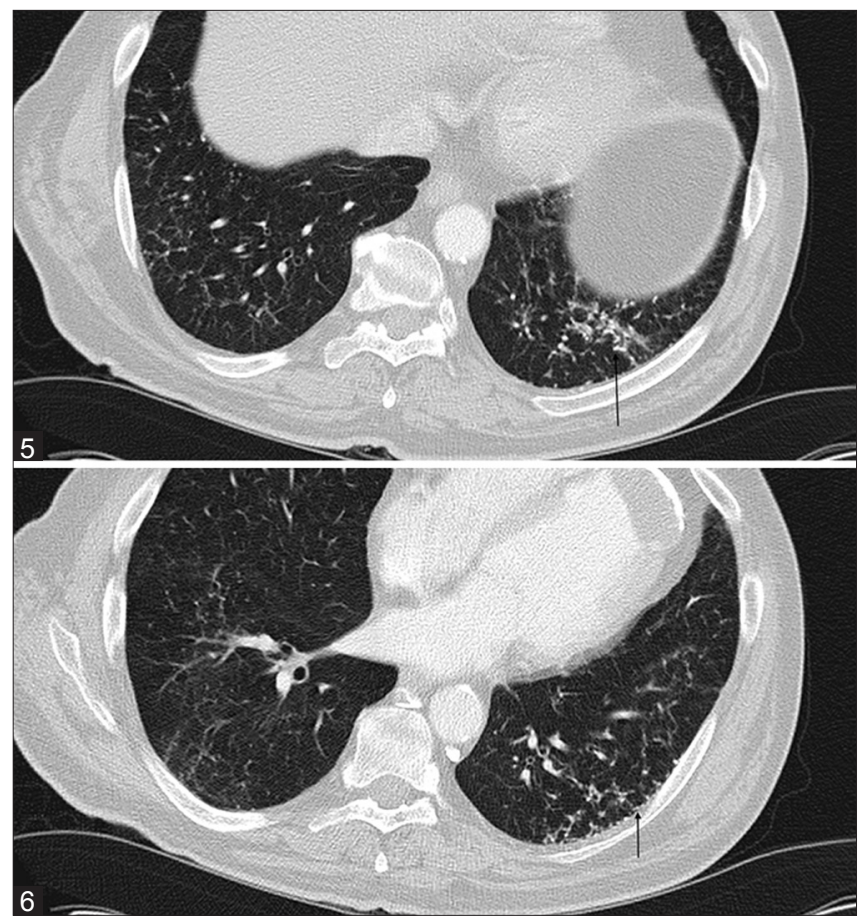

Figures 5 and 6: CT images show the clustered calcific densities in the left lower lobe associated with fibrosis (arrows)

mitral valve stenosis. However, it can develop with any condition leading to chronic pulmonary edema and pulmonary venous hypertension. ${ }^{[3,4]}$ On imaging, it typically presents as densely calcified, smooth, round nodules of 1-5 $\mathrm{mm}$ size that can often be mistaken for healed disseminated granulomatous infection such 
Table 1: Differential diagnosis of pulmonary calcifications and ossifications

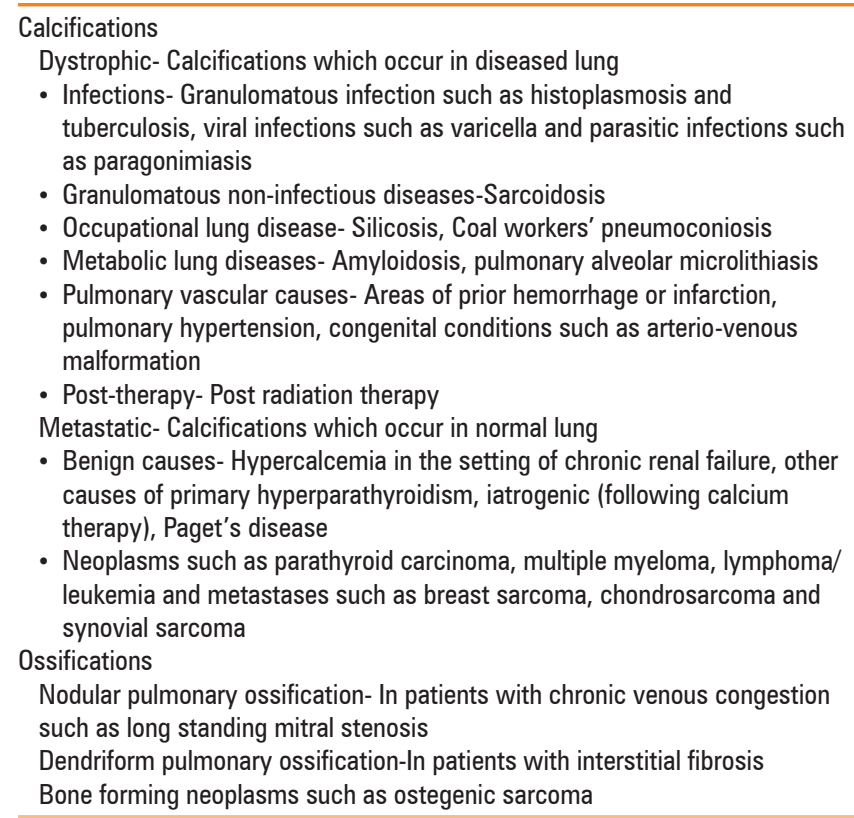

as histoplasmosis. Histologically, nodular pulmonary ossification (NPO) appears as a rounded calcified or ossified mass within an expanded alveolus. ${ }^{[5]}$ Unlike dendriform pulmonary ossification (DPO), NPO is usually devoid of marrow elements or fat. ${ }^{[5]}$

The dendriform type of ossification (named because of the dendritic appearance) usually occurs in the setting of chronic inflammation, including interstitial fibrosis; $;[6,7]$ however, sometimes it is idiopathic. It most commonly occurs in men in their fifth and sixth decades of life. Other conditions in which the dendriform pattern has been described include amyloidosis, asbestos exposure, busulfan therapy, and cystic fibrosis. ${ }^{[7,8]}$ On a chest radiograph, it manifests as delicate, branching linear interstitial opacities. The picture may be indistinguishable from that of fibrosis, bronchiectasis, or lymphangitic spread of tumor. It preferentially affects the alveolar interstitium, expanding the alveolar septa rather than the alveolar spaces. ${ }^{[5]}$

Although the exact pathogenesis of diffuse pulmonary ossification is unknown, it has been shown that underlying fibrosis is the precursor of DPO. ${ }^{[9]}$ It is thought to be due to metaplasia of pulmonary fibroblasts into osteoblasts in response to chronic insult rather than transformation of metastatic calcification into bone. Some authors have postulated that anoxia produces an acidic environment, which stimulates fibroblast proliferation and metaplastic osseous formation. ${ }^{[10]}$ As mentioned earlier, DPO usually has fat or marrow elements within the bony proliferations. ${ }^{[5]}$
Dendriform pulmonary ossification is slowly progressive and may be apparent radiographically as bilateral, lower lobe-predominant, nonspecific reticulonodular densities. CT is better than plain radiography for demonstrating the presence of calcium in the affected lung tissue and in delineating the associated lung disease. High-resolution CT scans of the chest reveal branching lines of calcifications of 1-4 mm width in a bronchovascular distribution. ${ }^{[7]}$ The appearance of DPO is fairly characteristic on CT and can be easily distinguished from other diffuse causes of calcifications such as pulmonary alveolar microlithiasis, which typically have innumerable calcified micronodules. DPO can also be detected by bone methylene diphosphonate, which shows focal uptake of the bone-scanning agent (e.g., technetium-99m methylene diphosphonate). ${ }^{[11]}$ Thoracoscopic biopsy enhances the procurement of tissue to establish a clinical diagnosis. Accurate prognosis is difficult to determine as cases are generally diagnosed post mortem; however, most cases show little or no change over time. No treatment protocols are established and surveillance with annual pulmonary function tests and chest roentgenograms are recommended in patients with suspected diffuse pulmonary ossification.

To summarize, in this article we present two cases of DPO, a relatively rare entity that represents an interesting response of the lung parenchyma to chronic injury. Knowledge of this entity is important for radiologists and clinicians alike so that the condition is not confused with other forms of calcium deposition or granulomatous processes.

\section{Acknowledgement}

We thank Dr. Carol Farver and Megan Griffiths for their assistance.

\section{References}

1. Kanne JP, Godwin JD, Takasugi JE, Schmidt RA, Stern EJ. Diffuse Pulmonary Ossification: Diffuse pulmonary ossification. J Thoracic Imaging 2004;19:98-102.

2. Popelka CG, Kleinerman J. Diffuse pulmonary ossification. Arch Intern Med 1977;137:523-525.

3. Galloway RW, Epstein EJ. Pulmonary ossific nodules in mitral valve disease. Br Heart J 1961;19:532-8.

4. Woolley K, Stark P. Pulmonary parenchymal manifestations of mitral valve disease. Radiographics 1999;19:965-72.

5. Lara JF, Catroppo, JF, Kim DU, da Costa D. Dendriform pulmonary ossification, a form of diffuse pulmonary ossification. Report of a 26-year autopsy experience. Arch Pathol Lab Med 2005;129:348-53.

6. Fernandez Crisosto CA, Quercia Arias O, Bustamante N, Moreno $\mathrm{H}$, Uribe Echevarria A. Diffuse pulmonary ossification associated with idiopathic pulmonary fibrosis. Arch Bronconeumol 2004;40:595-8.

7. Gevenois PA, Abehsera M, Knoop C, Jacobovitz D, Estenne M. Disseminated pulmonary ossification in end-stage pulmonary fibrosis: CT demonstration. Am J Roentgenol 1994;162:1303-4. 
8. Chung MJ, Lee KS, Franquet T, Muller NL, Kwon OJ. Metabolic lung disease: Imaging and histopathologic findings. Eur J Radiol 2005;54:233-45.

9. Fried ED, Godwin TA. Extensive diffuse pulmonary ossification. Chest 1992;102:1614-5.

10. Jaderborg JM, Dunton RF. Rare clinical diagnosis of dendriform pulmonary ossification. Ann Thorac Surg 2001;71:2009-11.

11. Silberstein EB, Vasavada PJ, Hawkins H. Idiopathic pulmonary ossification with focal pulmonary uptake of technetium-99m HMDP bone scanning agent. Clin Nucl Med 1985;10:436.

Cite this article as: Jamjoom L, Meziane M, Renapurkar RD. Dendriform pulmonary ossification: Report of two cases. Indian J Radiol Imaging 2013;23:15-8

Source of Support: Nil, Conflict of Interest: None declared.

\section{Author Help: Online submission of the manuscripts}

Articles can be submitted online from http://www.journalonweb.com. For online submission, the articles should be prepared in two files (first page file and article file). Images should be submitted separately.

1) First Page File:

Prepare the title page, covering letter, acknowledgement etc. using a word processor program. All information related to your identity should be included here. Use text/rtt/doc/pdf files. Do not zip the files.

2) Article File:

The main text of the article, beginning with the Abstract to References (including tables) should be in this file. Do not include any information (such as acknowledgement, your names in page headers etc.) in this file. Use text/rtf/doc/pdf files. Do not zip the files. Limit the file size to $1024 \mathrm{~kb}$. Do not incorporate images in the file. If file size is large, graphs can be submitted separately as images, without their being incorporated in the article file. This will reduce the size of the file.

3) Images:

Submit good quality color images. Each image should be less than $\mathbf{4 0 9 6} \mathbf{~ k b ~ ( 4 ~ M B ) ~ i n ~ s i z e . ~ T h e ~ s i z e ~ o f ~ t h e ~ i m a g e ~ c a n ~ b e ~ r e d u c e d ~ b y ~ d e c r e a s - ~}$ ing the actual height and width of the images (keep up to about 6 inches and up to about $1800 \times 1200$ pixels). JPEG is the most suitable file format. The image quality should be good enough to judge the scientific value of the image. For the purpose of printing, always retain a good quality, high resolution image. This high resolution image should be sent to the editorial office at the time of sending a revised article.

4) Legends:

Legends for the figures/images should be included at the end of the article file. 